\title{
Design de Moda e Design Estratégico: análise do deslocamento da técnica de moulage para a etapa metaprojetual
}

\author{
Prof $^{a}$. Me. Luciene Machado \\ Universidade do Vale do Rio dos Sinos - UNISINOS \\ luka_mac@hotmail.com \\ Prof. Dr. Celso Carnos Scaletsky \\ Universidade do Vale do Rio dos Sinos - UNISINOS \\ celsocs@unisinos.br
}

Resumo: O Design de Moda e o Design Estratégico são duas subáreas do Design de caráter projetual que utilizam técnicas de representação como forma de tangibilizar o conceito do projeto. Dentre as modalidades de representação na Moda está a moulage. A moulage é uma técnica francesa de modelagem tridimensional, na qual se molda o tecido diretamente sobre o manequim de costura, aplicada geralmente no final do processo de Moda, na etapa de Modelagem. O Design Estratégico propõe o desenvolvimento de meios de pensar o processo de design através de um método, denominado metaprojeto. O metaprojeto antecede a etapa projetual e consiste na pesquisa e interpretação de informações, cujo foco é pensar e questionar sobre os aspectos do problema de design, a fim de direcionar à geração de conceitos de projeto. Este artigo propõe uma associação entre o Design de Moda e o Design Estratégico e suas respectivas ferramentas projetuais - a técnica de moulage e o metaprojeto. Mostra os resultados de uma pesquisa de caráter exploratório concluída, que teve como objetivo analisar os efeitos do deslocamento da técnica de moulage para a etapa metaprojetual na construção de conceitos de projeto. O método utilizado consistiu em aplicar um Exercício Projetual a oito duplas, formadas por um designer de moda e um designer, os quais buscaram solucionar um briefing de Design de Moda, utilizando a moulage para elaborar conceitos de projeto. Os resultados apontaram que a moulage, sendo utilizada de modo experimental durante a etapa metaprojetual, contribuiu como um estímulo para potencializar a geração e a representação das ideias iniciais dos designers participantes, bem como, para construir e visualizar o conceito de projeto gerado.

Palavras-chave: Moulage, Design de Moda, Design Estratégico, Geração de Ideias, Representação. 


\begin{abstract}
Fashion Design and Strategic Design are two subareas of Design with projectual character that use design representation techniques as a way to visualize the design concept. Among the modes of representation in Fashion is the draping. Draping is a French technique of three-dimensional modeling, in which the fabric is shaped directly on the sewing mannequin, usually applied in the end of the fashion process in the Modeling Stage. The Strategic Design proposes to develop ways of thinking about the design process through a method called metaproject. The metaproject precedes the projetual phase and constitutes in research and interpretation of information, which focus in thinking and questioning the aspects of design problem, in order to generate design concepts. This paper proposes an association between Fashion Design and Strategic Design and their respective design tools - the draping technique and the metaproject. It shows the results of an exploratory concluded research which the aim was to analyze the effects of the displacement of draping to the metaprojetual phase to build design concepts. The method was to apply a Projetual Exercise with eight pairs of designers, formed by a fashion designer and a designer, to solve a Fashion Design briefing, using the draping technique to build design concepts. The results showed that draping, being used experimentally during the metaprojetual phase, contributed as a stimulus to enhance the generation and the representation of the designers' early ideas, as well as it helped to build and visualize the design concept.
\end{abstract}

Keywords: Draping technique, Fashion Design, Strategic Design, Idea Generation, Representation.

\title{
1. INTRODUÇÃO: O DESIGN ESTRATÉGICO E A TÉCNICA DE MOULAGE
}

Esta pesquisa propôs uma associação entre a técnica de moulage do Design de Moda e um método do Design Estratégico, denominado de metaprojeto.

A moulage é uma técnica francesa de modelagem tridimensional, na qual se molda o tecido diretamente sobre o manequim de costura, o qual possui as medidas anatômicas do corpo humano, ou mesmo sobre o próprio corpo, de modo a se obter marcações para a construção de um molde, aplicada geralmente no final do processo de Moda, na etapa de Modelagem (DUBURG e TOL, 2012). Pode ser utilizada de modo tradicional e experimental. Na moulage tradicional (Moulage 1 na Figura 1), como o objetivo é a construção de moldes para a confeç̧ão de peças de vestuário, é necessário marcar o manequim com fitas (fitilhamento), trabalhar com medidas precisas (comprimento, largura e profundidade), usar somente o tecido (o algodão cru que não tem cor para não interferir na forma e visualização do modelo), e ser realizada no final do processo de Moda, na etapa de Modelagem, após a definição do modelo da peça, como propõem Treptow (2003).

Figura 1 - Moulage tradicional e experimental. 


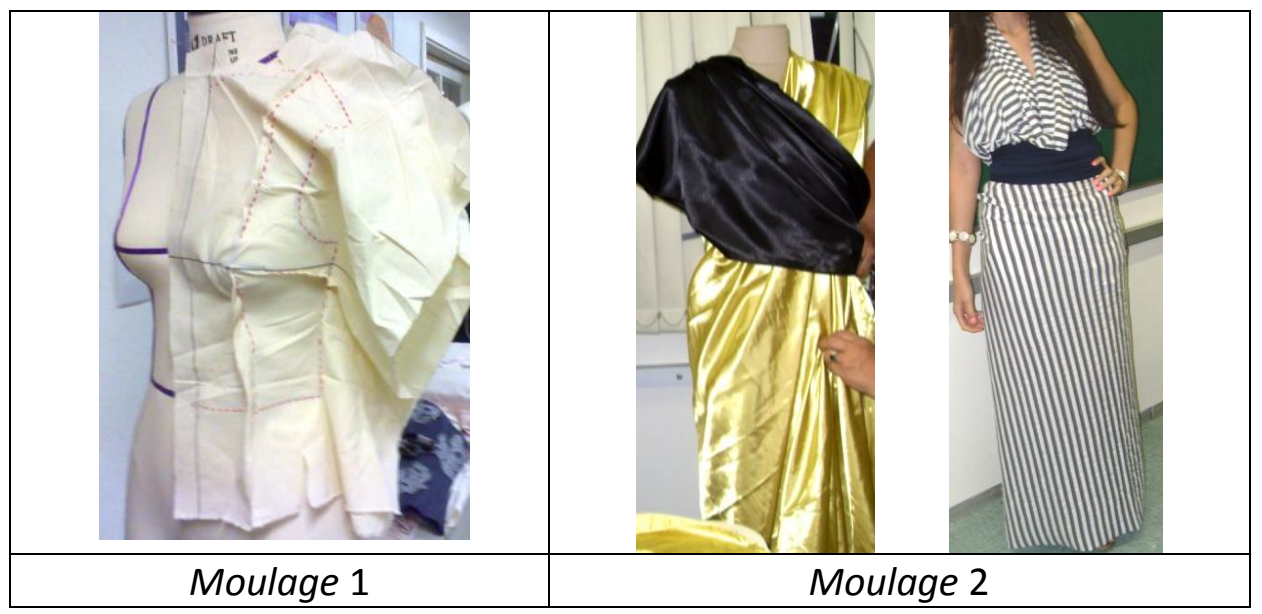

Fonte: Elaborado pelo autor, com base na pesquisa realizada.

A moulage usada de modo experimental (Moulage 2 na Figura 1) é realizada de modo mais livre, no sentido de não se preocupar com medidas precisas e sem fazer o fitilhamento, já que o intuito não é construir moldes. Pode-se trabalhar com diversos tipos de tecidos, gramaturas e cores distintas, bem como, utilizados os não tecidos, como plásticos, papéis, TNT, entre outros. De modo experimental, a moulage pode ser utilizada: (1) como auxílio aos esboços de moda, quando não se consegue visualizar e desenhar volumes complexos da peça, na etapa de Geração de Alternativas (meio do processo), como propõem Rech (2002) e Montemezzo (2003); (2) para elaborar uma roupa de modo rápido no próprio corpo ou no manequim e pronta para vestir, podendo utilizar amarrações e pequenas costuras. A moulage usada de modo experimental foi o enfoque desta pesquisa.

O Design Estratégico propõe o desenvolvimento de meios de pensar o processo de design com uma abordagem holística unindo criatividade, multidisciplinaridade e inovação através de um método, denominado metaprojeto ou etapa metaprojetual. Este é uma fase que antecede a etapa projetual e consiste na pesquisa e interpretação de informações, cujo foco é pensar e questionar sobre os aspectos do problema de design para direcionar à geração de propostas conceituais de projeto, denominadas concepts (ou conceitos de projeto). Neste sentido, o metaprojeto atribui uma dimensão estratégica ao design (CELASCHI e DESERTI, 2007). O concept é a representação esquemática e visualizada de uma ideia ou de uma solução em resposta a um problema de design proposto (CAUTELA, 2007) e tem como função reposicionar o problema por meio de sua reflexão. Um concept de Design Estratégico deve proporcionar a visualização de um sistema produto-serviço através de técnicas de representação, como, moodboards, desenhos, modelos e protótipos.

Tanto o Design Estratégico quanto a Moda são áreas de caráter projetual e criativo que utilizam técnicas de representação como forma de tangibilizar e visualizar o conceito do projeto. Dentre as modalidades de representação na Moda está a moulage. Nesta pesquisa, o objetivo foi analisar os efeitos do deslocamento da técnica moulage para a etapa metaprojetual na construção de conceitos de projeto (concepts). Utilizou-se o termo "concept(s)" proveniente do Design Estratégico para se referir ao(s) "conceito(s) de projeto". A seguir o método da pesquisa e o Exercício Projetual.

\section{O MÉTODO E O EXERCÍCIO PROJETUAL}


Com o caráter de uma pesquisa exploratória e qualitativa, realizou-se um Exercício Projetual que consistiu em solucionar um briefing de moda proposto a 16 participantes voluntários que trabalharam divididos em oito duplas (G1 a G8), cada qual composta por um designer de moda (M1 a M8) e um designer (D1 a D8), ambos com conhecimentos sobre o Design Estratégico. Os designers de moda eram profissionais, com conhecimentos e alguma habilidade sobre a moulage, sem a necessidade de serem especialistas. Os designers eram profissionais, com alguma habilidade em representação tridimensional (modelos, protótipos), sem habilidades com a moulage. O exercício foi filmado, fotografado e complementado por anotações de observações, sendo dividido em três momentos: (1) explicação e demonstração da moulage; (2) apresentação do briefing ("Desenvolver um concept para um vestuário inteligente: a roupa do futuro 100 anos à frente") e das pesquisas; (3) execução do exercício utilizando a moulage para construir um conceito de vestuário do futuro (60 minutos), podendo consultar o material visual impresso sobre a problemática do exercício. Posteriormente, na mesma sala, foram realizadas as entrevistas individuais, que tiveram o áudio gravado.

Como o foco da pesquisa foi a moulage de modo experimental, foram utilizados os seguintes materiais: tecidos (voil e tricoline), não-tecidos (TNT, papel kraft, plástico bolha), alfinetes, fita adesiva, barbante, quatro manequins (dois femininos e dois masculinos). Todos estes materiais eram de cor neutra (branco e bege) para proporcionar melhor visualização do modelo a ser criado. As técnicas de coleta de informações provenientes do Exercício Projetual foram observação direta nãoparticipante, análise dos documentos e entrevistas em profundidade. Os documentos produzidos foram as filmagens, fotos, entrevistas e anotações registradas das observações. Através das transcrições dos vídeos e das entrevistas e utilizando a técnica de análise de conteúdo segundo os critérios de Moraes (1999) e Bardin (2011), chegou-se a três categorias de análise do Exercício Projetual (Problema, Geração de Ideias e Representação), através das quais os resultados da pesquisa foram organizados e apresentados, como seguem.

\section{RESULTADOS}

O processo da construção do concept envolveu os momentos de reflexão do problema (Categoria 1), de geração de ideias (Categoria 2) e de representação (Categoria 3). A partir da observação dos vídeos, por meio dos diálogos e das ações dos participantes foi construído o Quadro 1, que apresenta as três categorias identificadas durante o exercício: Problema (cor verde); Geração de Ideias (cor amarelo, identificadas por meio de números); Representação (cor rosa). Neste, o tempo do exercício (de 1 a 60 minutos) está representado na primeira linha e as duplas (G1 a G8) na primeira coluna à esquerda.

Quadro 1 - Categorias analisadas. 


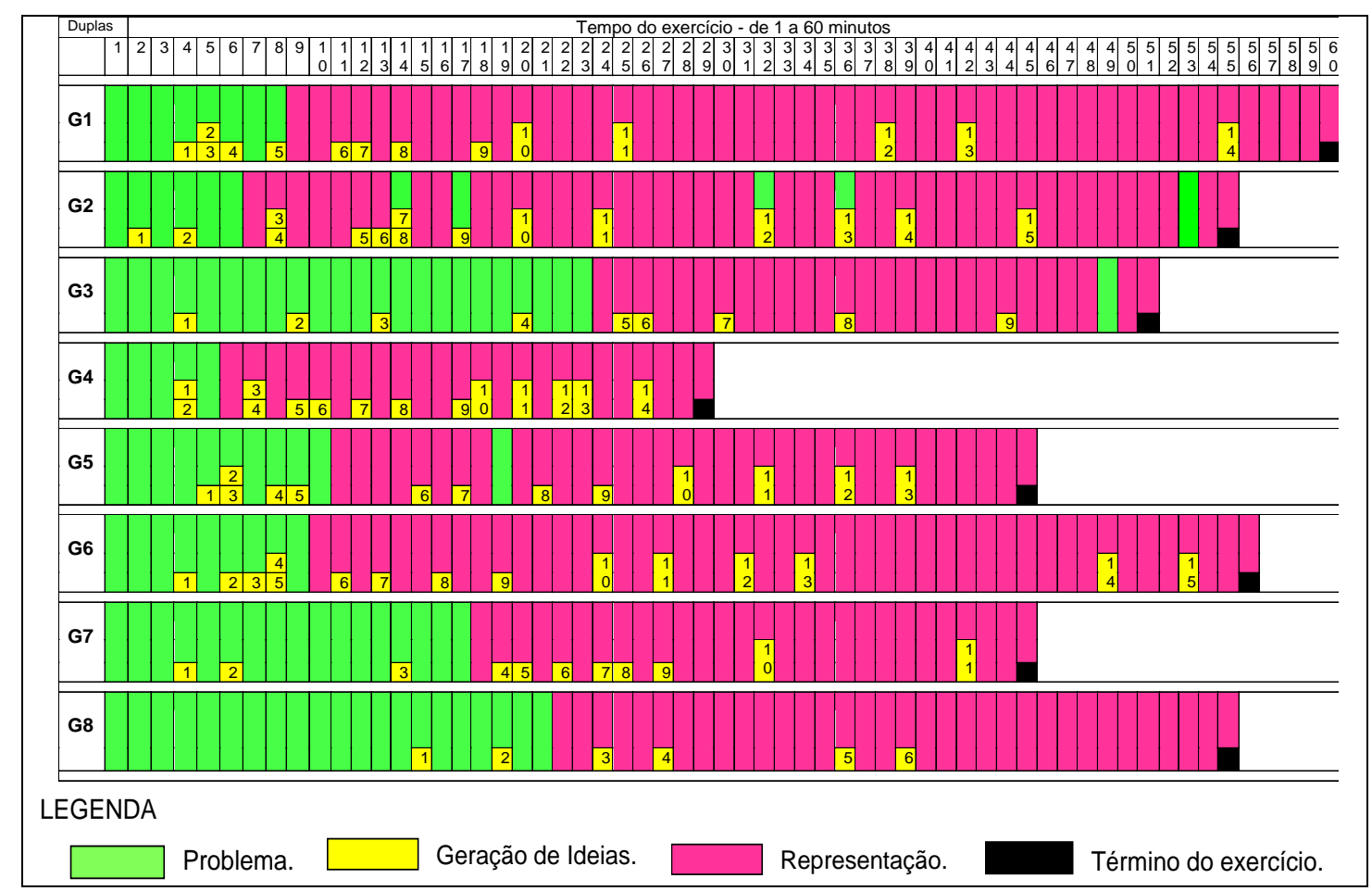

Fonte: Elaborado pelo autor, com base na pesquisa realizada.

Observou-se que as duplas não definiram um concept fechado no início do exercício durante reflexão do problema. O concept foi sendo construído ao longo do processo a partir de ideias iniciais que foram relacionadas a outras novas ideias geradas com a moulage. Notou-se pelos vídeos e entrevistas que todas as duplas agiram do mesmo modo em seu processo para desenvolver o concept. Primeiro, houve um momento de reflexão sobre o problema e o briefing através da consulta do material impresso. Após, as duplas começaram a lançar ideias iniciais, ainda vagas, sobre como seria a roupa do futuro. Em seguida, começaram a representação de suas ideias iniciais com a manipulação dos tecidos sobre o manequim.

Notou-se que em todas as duplas o momento de representação com a moulage foi maior que o de reflexão do problema. Durante a representação através da moulage, as duplas geraram novas ideias as quais iam sendo materializadas no manequim. Durante os momentos de representação, algumas duplas $(G 1, G 2, G 4, G 7)$ pararam de modelar por breves instantes e começaram a refletir sobre a moulage realizada.

Durante tais reflexões, os participantes puderam perceber se o que realizaram estava de acordo com suas ideias iniciais, bem como, se o material escolhido para a representação estava adequado. Deste modo, os participantes tomaram decisões e fizeram questionamentos, no sentido de acrescentar ou retirar alguns dos materiais que modelaram, alterar formas e volumes e transformar suas ideias ou até mesmo gerar outras novas através da representação. Esta tomada de decisão em meio a uma ação projetual, além da reflexão e questionamentos, caracteriza o metaprojeto.

A Figura 2 mostra um fluxograma do processo de construção do concept pelas duplas, durante a observação do Exercício Projetual.

Figura 2 - Processo de construção do concept pelas duplas. 


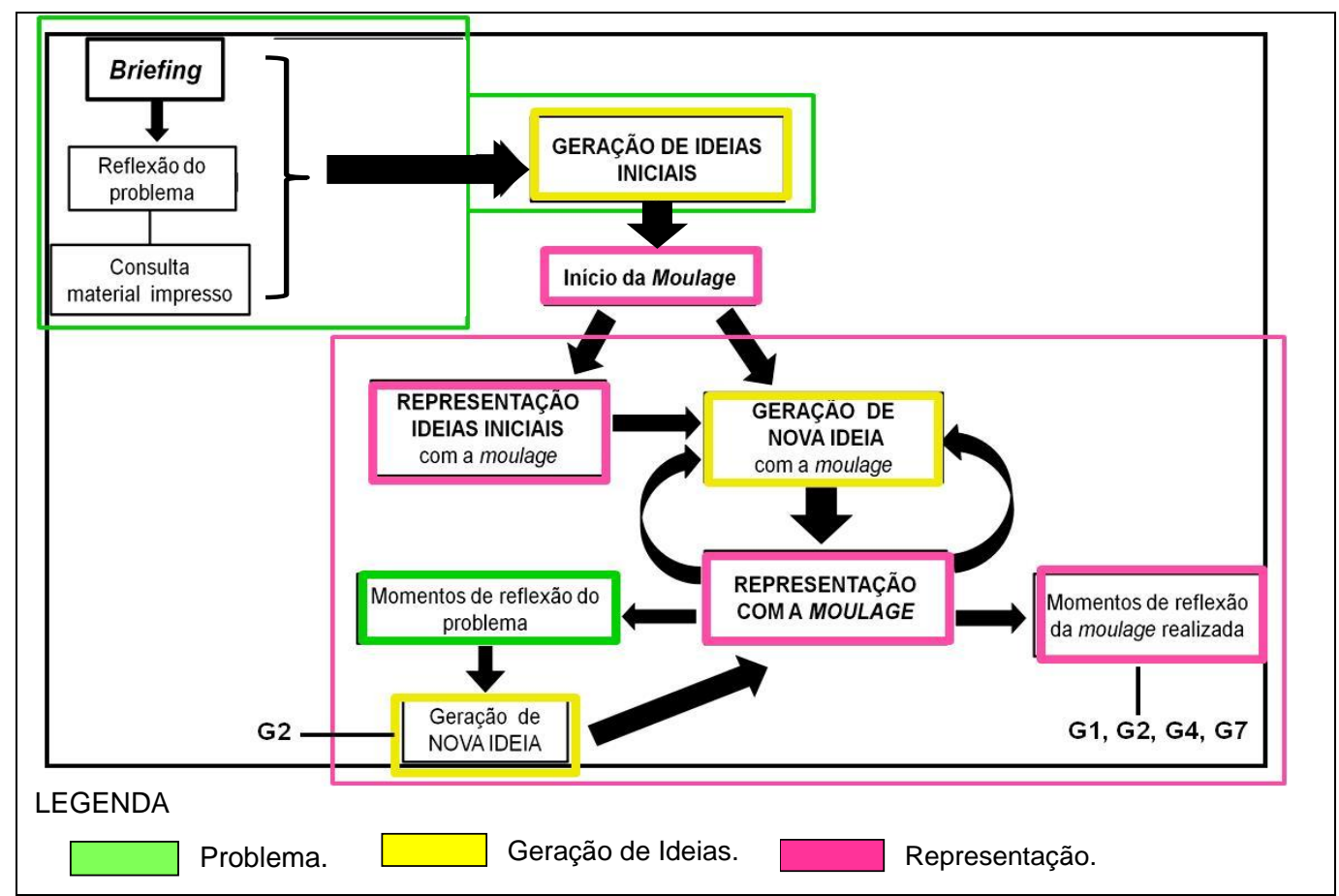

Fonte: Elaborado pelo autor, com base na pesquisa realizada.

Em seguida, a descrição dos resultados em cada categoria analisada.

\subsection{Categoria Problema}

Essa categoria consistiu na identificação dos momentos de reflexão do problema e na análise do processo de sua reflexão por cada dupla. Observou-se que todas as duplas refletiram sobre o problema por mais tempo no início do exercício, como mostra o Quadro 1.

Quanto ao processo de reflexão do problema no início do exercício, através dos vídeos observou-se que a maioria das duplas $(\mathrm{G} 1, \mathrm{G} 2, \mathrm{G} 4, \mathrm{G} 5, \mathrm{G} 6)$ teve um processo inicial de reflexão do problema semelhante, mais direto e em curto tempo (entre 5 a 10 minutos), no qual os participantes discutiram brevemente sobre o briefing, características que a roupa poderia ter e logo iniciaram a moulage, tomando decisões rápidas, como exemplificado na Figura 3.

Figura 3 - Processo de reflexão do problema da dupla G2.

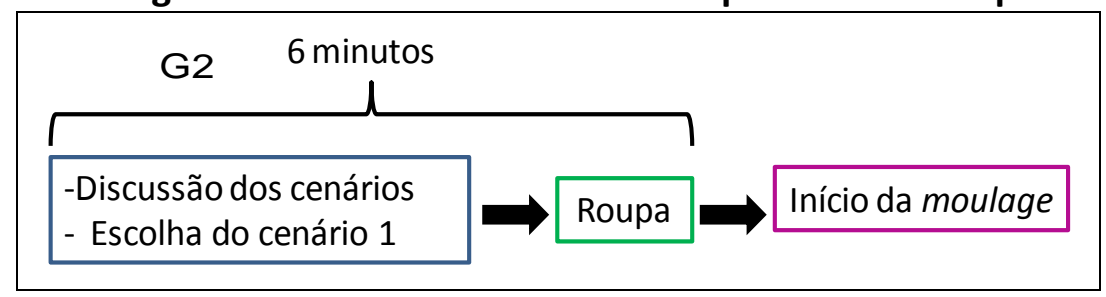

Fonte: Elaborado pelo autor, com base na pesquisa realizada.

Em oposição, uma minoria $(G 3, G 7, G 8)$ apresentou um processo de reflexão do problema mais aberto e longo (entre 17 e 23 minutos), no qual questionaram várias vezes sobre as roupa, antes de iniciar a moulage, como exemplificado na Figura 4.

Figura 4 - Processo de reflexão do problema da dupla G7. 


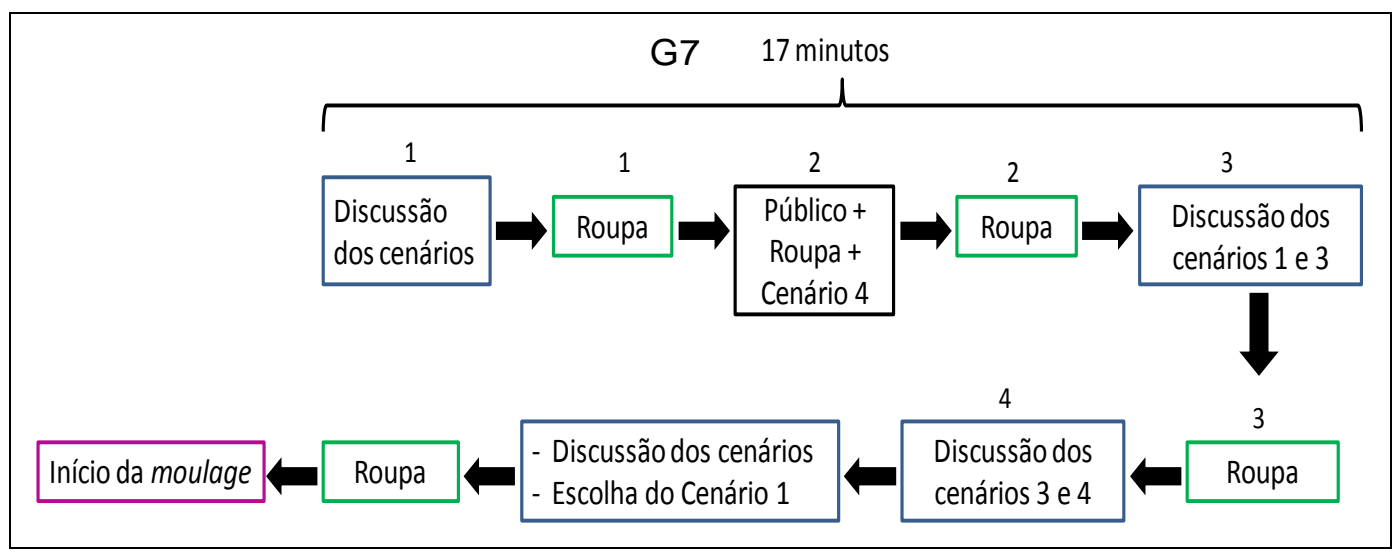

Fonte: Elaborado pelo autor, com base na pesquisa realizada.

Independente do processo das duplas ser mais direto ou aberto, observou-se que todas as duplas conseguiram refletir sobre o problema e o briefing antes de iniciar a moulage. Notou-se dois tipos de comportamentos no que se refere a reflexão do problema. Enquanto algumas duplas $(\mathrm{G} 1, \mathrm{G} 4, \mathrm{G6}, \mathrm{G7}, \mathrm{G} 8)$ refletiram sobre o problema somente no início do exercício, outras $(G 2, G 3, G 5)$ além de refletirem no início, pararam o uso da moulage por instantes e retomaram o problema brevemente durante e no final do exercício, realizando breves discussões sobre o mesmo, como mostra o Quadro 1. Estes momentos de reflexão sobre o problema foram estimulados pela própria técnica de moulage de forma visual e tátil durante o exercício e apontam que o problema estava presente na mente dos participantes das referidas duplas durante todo o processo. No contexto restrito das duplas observadas (G1 a G8), podese dizer que a reflexão sobre o problema durante a modelagem indica ser possível deslocar a moulage para a etapa metaprojetual.

\subsection{Categoria Geração de Ideias}

Essa categoria compreendeu analisar como foi o processo de geração de ideias para criar um concept e se os participantes conseguiram gerar ideias enquanto utilizavam a técnica de moulage. Foi analisado, igualmente, se durante o Exercício Projetual houve ausência, bloqueio ou fluidez de ideias com a utilização da moulage. Observou-se que as duplas geraram suas ideias de dois modos: (1) a partir da consulta do material visual impresso nos momentos de reflexão do problema no início do exercício (cor amarela sobre cor verde no Quadro 1); (2) a partir do manuseio dos materiais sobre o manequim nos momentos de uso da moulage durante o exercício (cor amarela sobre cor rosa no Quadro 1).

Quanto às ideias geradas nos momentos de reflexão do problema, todas as duplas geraram algumas ideias iniciais ainda vagas, as quais orientaram o início da moulage e fizeram parte do concept. Essas primeiras ideias foram estimuladas pelas imagens do material visual impresso (moodboards do vestuário inteligente) as quais serviram como mapas de orientação a respeito de um possível futuro, bem como, forneceram um repertório de sugestões e estímulos para que as duplas pudessem gerar suas ideias iniciais. Para exemplificar esse fato, segue a Figura 5 que mostra uma das ideias iniciais geradas por G5 (Ideia 1 - roupa inflável com gomos), a qual foi representada, posteriormente, no momento de uso da moulage. 
Figura 5 - Ideia 1 gerada no momento de reflexão do problema, estimulada pelo material visual impresso - Dupla G5.

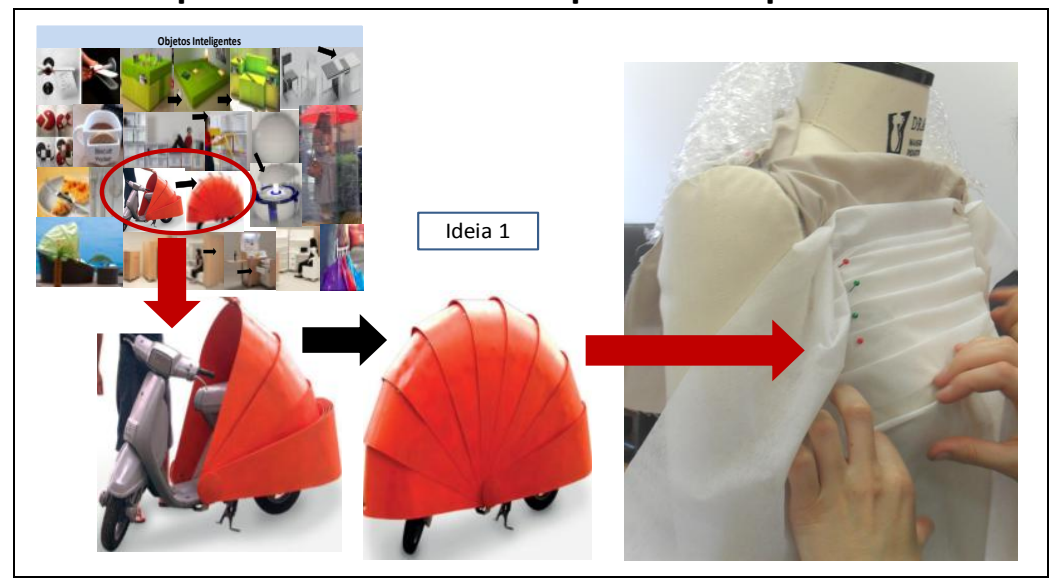

Fonte: Elaborado pelo autor, com base na pesquisa realizada.

Notou-se que todas as duplas lançaram um menor número de ideias no momento inicial de reflexão do problema, sendo a maioria considerada e representada através da moulage: G2, G4 e G8 geraram duas ideias; G7 com 3 ideias; G3 com 4 ideias; G1, G5 e G6 com 5 ideias. Algumas duplas (G3, G6, G7) descartaram um menor número de ideias iniciais, as quais não foram trabalhadas pela moulage, por não estarem adequadas ao briefing. Quanto às ideias geradas nos momentos de uso da moulage (estimuladas pela própria técnica), percebeu-se que o fato da técnica trabalhar com o manuseio de materiais tridimensionais (tecidos, papel, plástico bolha) sobre uma superfície também tridimensional (o manequim), proporcionou uma maior percepção tátil, além da visual, fazendo com que se tivesse a sensação de realidade pela escala 1:1 do manequim e propiciando a visualização simultânea de todas as vistas. Notou-se que todas duplas geraram uma maior quantidade de ideias durante 0 uso da moulage - G8 gerou quatro ideias; G3 cinco ideias; G2, G5 e G7 oito ideias; G1 nove ideias; G6 10 ideias; G4 com 12 ideias. Essas ideias geradas com a moulage foram consideradas e representadas através da própria técnica, como mostra a Figura 6.

Figura 6 - Ideias geradas nos momentos de uso da moulage, estimuladas pela própria técnica de moulage - Dupla G2.

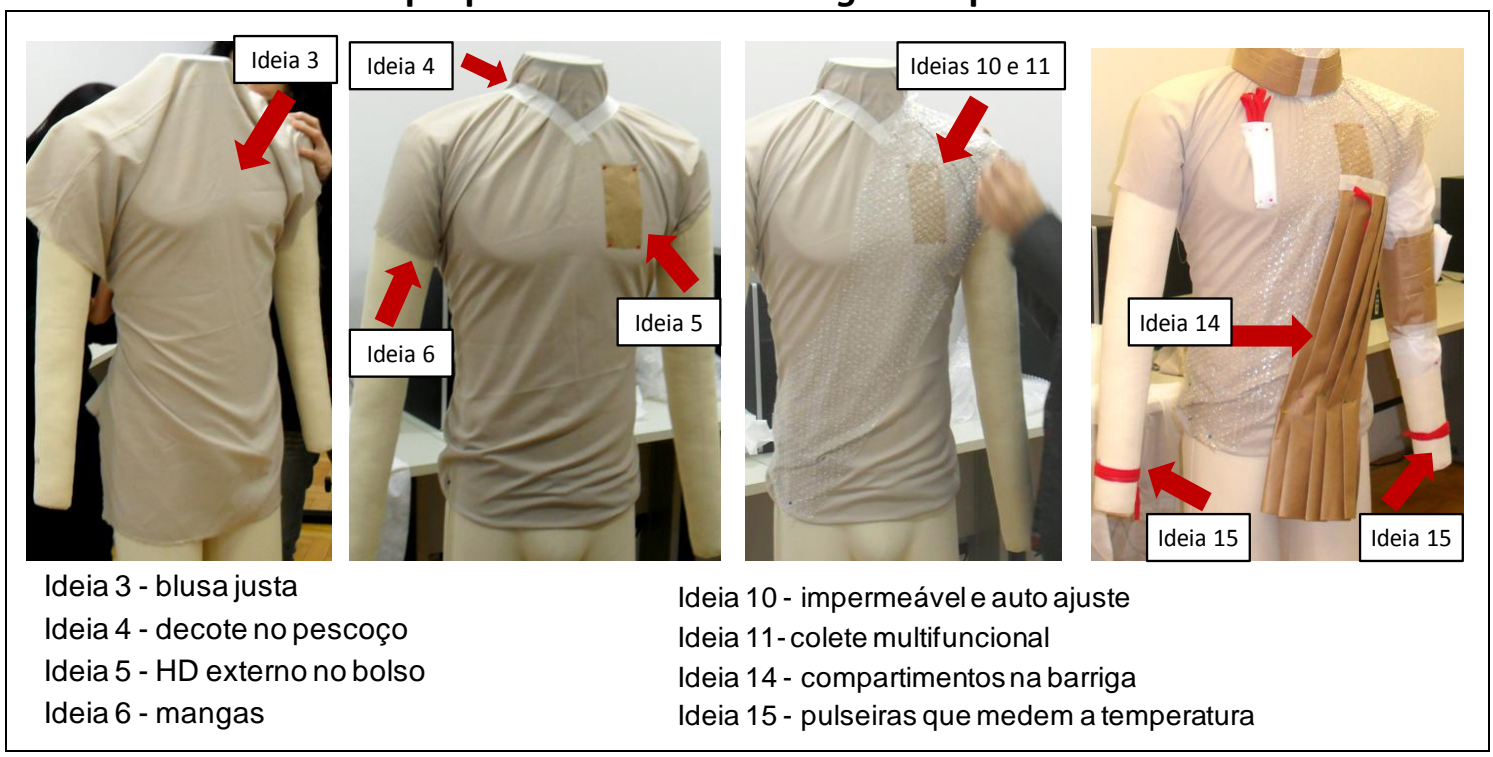


Fonte: Elaborado pelo autor, com base na pesquisa realizada.

Pela observação e relatos dos participantes, percebeu-se que à medida que os mesmos modelavam, suas ideias iniciais tomavam forma e iam sendo detalhadas e desenvolvidas, bem como, outras novas ideias iam surgindo, sendo agregadas e complementando as ideias iniciais, para deste modo, formar um concept no final do exercício. Assim, pôde-se verificar que não houve um bloqueio ou ausência de ideias durante o uso da moulage. A moulage proporcionou o aparecimento de ideias ao acaso, ao se fazer uma dobra, um recorte, um franzido nos tecidos e a partir de diferentes texturas, tanto dos materiais disponibilizados quanto das texturas criadas por algumas duplas. Essas ideias inesperadas devem-se a própria técnica de moulage autorizar uma fluidez de movimentos, os quais vão sendo executados em sequência e sem interrupção, sendo que o designer decide se aceita ou rejeita cada movimento a executar. Assim, as ideias geradas nos momentos de reflexão do problema e nos de uso da moulage construíram o concept. Deste modo, notou-se que a moulage contribuiu para visualizar e materializar o concept, ou seja, "fazer ver", como afirma Zurlo (2010). A técnica também contribuiu significativamente para a geração e a discussão de ideias, proporcionando um processo contínuo e sem interrupção, com uma significativa interação com o plano tridimensional. Este fato pode ser considerado como outro indício positivo para se deslocar a moulage para a etapa metaprojetual.

\subsection{Categoria Representação}

Essa categoria compreendeu analisar os aspectos materiais do uso da técnica de moulage como a linguagem tridimensional, que correspondeu ao entendimento da relação entre forma/volume/dimensão/material, da visualização das vistas do manequim, das cores, da atribuição de significados aos materiais e da escala 1:1. Notou-se que em todas as duplas o momento de representação com a moulage foi maior que o de reflexão do problema, como mostrado o Quadro 1 pela cor rosa. A representação através da técnica de moulage foi facilitada pelos materiais têxteis (tecidos, TNT, papel kraft e plástico bolha) e pelo manequim, os quais estimularam a percepção visual e tátil. Todas as duplas atribuíram significados e funções às diferentes texturas dos materiais têxteis e às texturas criadas, relacionando-as com alguma parte tecnológica da roupa e/ou com tecidos tecnológicos e inteligentes que realizavam diversas funções. Essas atribuições de significados fizeram parte do concept que estava sendo elaborado. Verificou-se que a moulage possibilitou a criação de texturas que poderiam não acontecer em duas dimensões, segundo o relato dos participantes. Algumas duplas (G1, G2, G4, G5) se destacaram por criar superfícies com texturas por meio de dobraduras do TNT e do papel kraft para representar o conceito de um tecido tecnológico, como exemplificado nas imagens da Figura 5 e Figura 6 . Isso indicou que a moulage proporcionou desenvolver a estética das formas através do manuseio, modelagem e dobradura dos materiais, de modo a proporcionar melhor compreensão, devido à visualização tridimensional.

Todos os participantes afirmaram que trabalhar com materiais de cores neutras proporcionou focar mais na modelagem, na criação e visualização da forma, no comportamento dos materiais, na estrutura da peça e na construção do concept. Deste modo, observou-se que todas as duplas conseguiram representar suas ideias com a moulage e com os materiais tridimensionais, do ponto de vista da forma, de definir 
proporções, de unir e modelar diferentes materiais, de criar texturas a partir de dobraduras e drapeados e de adequar os volumes anatomicamente sobre o manequim. Segundo a maioria dos participantes, a escala 1:1 e volumétrica do manequim proporcionou uma maior percepção de realidade para construir a peça imaginada tridimensionalmente, em relação a construí-la em um plano bidimensional (como no desenho ou no molde plano). Outros relataram que modelar em um tamanho natural facilitou visualizar as proporções, os volumes, as vistas, permitiu fazer ajustes, trocar os tecidos de lugar e fazer as devidas correções. Isso se deve à moulage simular a modelagem em uma pessoa real, pela ergonomia e tamanho do manequim, possibilitar ver o caimento, comportamento e quantidade dos diferentes materiais, permitir tocar na peça, sentir a textura dos materiais e criar novas texturas a partir de dobraduras, franzidos e drapeados.

Alguns participantes apontaram a questão lúdica da técnica de moulage, pela interação com o manequim de escala natural, onde é possível construir e desconstruir formas, montar e desmontar o tecido, modelar como se fosse uma escultura de tecido. Outros atribuíram à moulage um caráter artístico e livre, por ser trabalhada de modo experimental a partir do manuseio dos materiais tridimensionais e da moldagem dos mesmos sobre o manequim, não tendo a precisão de medidas e a preocupação de construção de um molde. A possibilidade da construção da roupa acontecer no plano tridimensional faz com que se desenvolvam habilidades visuais e sensoriais, onde se torna necessário perceber novas formas. Nesse sentido, mesmo os participantes que não conheciam a técnica de moulage (os designers que não pertenciam à área da moda) relataram que se sentiram mais livres e conseguiram expressar suas ideias utilizando a técnica.

Assim, o uso da moulage pode ser considerado como facilitador da representação, além de estimularem a produção de ideias pelos seguintes aspectos: o uso de cores neutras; a escala volumétrica do manequim; os materiais tridimensionais; a atribuição de significados aos materiais; a criação de texturas; os aspectos lúdico, livre e artístico da moulage; a experimentação de formas e materiais diversos; e o modo tridimensional de pensar durante o uso da moulage. Todos estes fatores descritos parecem ser sinais que evidenciam a pertinência do deslocamento da técnica de moulage experimental para a etapa metaprojetual, a fim de tangibilizar as ideias de modo a visualizá-las tridimensionalmente, utilizando-a para auxiliar na elaboração e refinamento do concept, podendo fomentar a geração de alternativas.

\section{CONCLUSÃO}

Durante o início do exercício, observou-se que para alguns participantes que não pertenciam à área da moda, houve certo estranhamento em ter que usar a moulage como única técnica de representação, sem poder escrever ou desenhar antes de iniciar a modelagem. Isso se deve ao fato de que o uso da escrita e do desenho faziam parte do processo "tradicional" dos designers, antes da etapa de elaboração de modelos. Tal fato pode ser caracterizado como uma limitação da pesquisa. Entretanto, mesmo assim, observou-se que tais participantes, ao iniciarem o manuseio dos tecidos, foram se acostumando e vendo que era algo como desenhar em três dimensões ou esculpir, além de serem apoiados pelos designers de moda, que tinham habilidades com a técnica. Isso indica que o uso da técnica de moulage de modo experimental não está relacionado ao conhecimento prévio da mesma, por seu caráter 
lúdico e de livre manipulação e experimentação de novos materiais. Do mesmo modo que a tridimensionalidade é um aspecto inerente à moulage, também foi constatada como um elemento importante no processo, pois proporcionou a visualização do concept pela escala 1:1, materiais, texturas criadas, formas e volumes utilizados. Os participantes afirmaram que a moulage foi suficiente no exercício, ao passo que proporcionou modificações ao longo do processo, a percepção de problemas de ordem formal e ergonômica que surgiam enquanto modelavam.

Mesmo não havendo um treinamento com a moulage antes do exercício, apenas uma breve explicação e demonstração sobre a técnica, os participantes relataram que não tiveram nenhuma dificuldade em usá-la de modo experimental para elaborar os concepts. Isso foi positivo, confirmando as expectativas quanto à contribuição da moulage na etapa metaprojetual. Assim, pôde-se estabelecer uma relação entre a técnica de moulage (proveniente do Design de Moda) e o concept (do Design Estratégico) no sentido de que a moulage proporcionou a visualização e a materialização tridimensional do concept, enquanto o mesmo estava sendo construído, proporcionando fazer correções, ajustes e questionamentos. Isto garante seu uso enquanto uma técnica na etapa metaprojetual. Deste modo, os participantes foram capazes de desenvolver concepts e refletir sobre o problema, inicialmente proposto. Contudo, não se pode afirmar qual dos concepts foi o melhor, pois não era o foco da pesquisa.

Entretanto, os participantes apontaram como um fator de desvantagem da moulage, o tempo, no sentido de que se demanda mais tempo para fazer uma única moulage, enquanto se pode fazer vários desenhos em um mesmo período. $O$ tempo de 60 minutos estabelecido no exercício fez com que a moulage fosse utilizada de modo experimental, como um esboço, para refletir sobre as ideias representadas e gerar outras novas. Independente de demandar mais tempo para ser realizada, concluiu-se que o uso da moulage na etapa metaprojetual pôde proporcionar novos rumos e consequentemente gerar alternativas diferenciadas de concepts, por apresentar um maior nível de detalhamento. Esta restrição suscita a oportunidade de continuidade da pesquisa, a qual não teve a pretensão de esgotar o assunto, mas buscar ampliar os conhecimentos sobre a aplicação de uma técnica tridimensional do Design de Moda - a moulage - deslocada para a etapa metaprojetual do Design Estratégico.

Em suma, os pontos relatados demonstraram que é possível associar a moulage ao Design Estratégico através de seu deslocamento para a etapa metaprojetual na elaboração de concepts, devido a contribuições relevantes da técnica de moulage, como: (1) proporcionou refletir sobre o problema e sobre a moulage realizada durante os momentos de representação com a técnica; (2) estimulou a geração de ideias para elaborar um concept; (3) representou as ideias de modo tridimensional; (4) proporcionou visualizar e materializar o concept por meio da representação tridimensional das ideias; (5) conseguiu refinar melhor uma ideia vaga por meio da representação; (6) propiciou o surgimento de acasos (novas ideias) que iam sendo incorporados no concept e o fluxo contínuo de ideias (à medida que se vai modelando, uma ideia levava à outra), pelo caráter lúdico, livre e experimental; (7) os materiais tridimensionais e escala real 1:1 proporcionaram aguçar a percepção tátil e visual, a experiência de montagem e manuseio da peça, a experimentação e teste de materiais distintos e também estimulou a forma de pensar de modo tridimensional dos participantes (os designers de moda e os designers); (8) possibilitou a análise e a 
avaliação do modelo durante a modelagem, e a explicação de uma ideia através da representação volumétrica, o que às vezes, nem sempre é possível com o desenho; (9) pela ação semelhante à ação de esculpir, torna-se uma técnica dinâmica, interativa, lúdica, proporcionando liberdade de criação sobre o corpo na busca do inusitado (em relação à forma, textura e volume), de se chegar a novas soluções à medida que se vai modelando; (10) a possibilidade de prototipar de modo rápido e experimental para representar as ideias, como um esboço, facilitou o entendimento do concept que foi sendo criado, pois no momento em que se gerava uma ideia, a mesma era imediatamente materializada tridimensionalmente; (11) permitiu visualizar com maior precisão a peça no corpo e todas as vistas simultaneamente, os defeitos, os ajustes, o que funcionou ou não, os volumes complexos, os encaixes, bem como, corrigir os erros na medida em que apareciam.

Associando-se o metaprojeto às fases iniciais do processo do Design de Moda (Pesquisa, Planejamento, Elaboração do Conceito), percebeu-se que a técnica de moulage, conforme abordada nesta pesquisa, pode também ser deslocada para a etapa de pesquisa do Design de Moda. Assim, de modo experimental, pode ser utilizada para auxiliar a interpretação das informações, direcionar o planejamento e estimular a geração de ideias para a construção de um conceito de projeto de moda inicial, ao invés de se restringir seu uso de modo tradicional nas etapas projetuais Geração de Alternativas (etapa de desenvolvimento de esboços, no meio do processo) e Modelagem (etapa de construção de moldes, no final do processo).

A técnica de moulage foi compreendida pelos participantes e utilizada de modo experimental como auxílio à construção de um concept (conceito de projeto) para um produto de moda. Assim, dentro do contexto dessa pesquisa, concluiu-se que é possível deslocar a moulage para a etapa metaprojetual, por ser uma técnica de representação que possibilitou visualizar e materializar o concept por meio da linguagem tridimensional, estimulou a geração de ideias durante a modelagem e permitiu aos participantes refletir e questionar sobre o que estavam construindo e sobre o problema para melhor compreendê-lo.

\section{REFERÊNCIAS}

BARDIN, Laurence. Análise de conteúdo. Lisboa: Edições 70, 2011.

CAUTELA, Cabírio. Strumenti di design management. Milão: Franco Angeli, 2007.

CELASCHI, Flaviano; DESERTI, Alessandro. Design e innovazione: strumenti e pratiche per la ricerca applicata, Roma: Carocci, 2007.

DUBURG, Annette; TOL, Rixt van der. Moulage: Arte e técnica no design de moda. Porto Alegre: Bookman, 2012.

MONTEMEZZO, Maria Celeste de Fátima Sanches. Diretrizes metodológicas para o projeto de produtos de moda no âmbito acadêmico. 2003. 97 f. Dissertação (mestrado) - Universidade Estadual Paulista, Curso de Pós-Graduação em Desenho Industrial.

MORAES, Roque. Análise de conteúdo. Revista Educação, v. 22, n. 37, p. 7-32, 1999.

RECH, Sandra Regina. Moda: por um fio de qualidade. Florianópolis: Udesc, 2002.

TREPTOW, Doris. Inventando moda planejamento de coleção. Brusque: D.Treptow, 2003.

ZURLO, Francesco. Design Strategico. Working Paper, 2010. 
